\title{
The Use of Metarhizium anisopliae and Beauveria bassiana as Fungal Pathogen to Control the Growth of Aedes aegypti Population: A Preliminary Result
}

\author{
Melanie $^{1}$, Z.D. Aliana ${ }^{2}$, N. Anggriani ${ }^{3}$, and A.K. Supriatna ${ }^{4}$
}

\begin{abstract}
Dengue disease which is transmitted by the vector mosquitoes Aedes aegypti is still prevalent in many tropical countries. Current intervention program in reducing the spread of the disease is by controlling the number of the vector mosquitoes to stay below certain level that unable to transmit the disease effectively, e.g by using insecticide. It is widely known that mosquito's resistance to insecticide creates more problems. An alternative way to control the growth of the vector mosquitoes is by the introduction of fungal pathogen disease to the mosquitoes. In this paper we discuss the potential use of fungal pathogen Metarhizium anisopliae and Beauveria bassiana to control the growth of dengue vectoral mosquitoes Aedes aegypti population in different mosquito life stages, i.e. larval and imago stages. We use different kind of fungal concentration to see its effect on the mosquito's death rate and to find the most effective concentration to use in reducing the survival of the Aedes aegypti. We found that in terms of the number mosquito's death, the Metarhizium is more effective than the Beauveria in killing the Aedes aegypti larva. However, if the fungal are introduced to the Aedes aegypti imagos then the opposite is true.
\end{abstract}

Keywords-Aedes aegypti, survival rate, fungal pathogen, Meharhizium anisopliae, Beauveria bassiana

\section{INTRODUCTION}

$\mathrm{D}^{\mathrm{B}}$ ENGUE disease is transmitted by the Aedes aegypti mosquitoes. The mosquitoes originaly came from Africa which then is transported all over the world, probably unintensionally, and well established especially in tropical countries [1]. The passive migration of this mosquito has created many problems in terms of dengue outbreak in many tropical countries. There are various program known to control the spread of dengue, such as the fumigation or fogging program which uses insecticides to the adult Aedes aegypti mosquitoes. Other program is by applying the insecticides to the larval stage of the mosquitoes. Fumigation is done by spraying of insecticides using the ultra low volume technology which was initiated in the early 1970s [2] and it

Melanie $^{1}$ and Z.D. Aliana ${ }^{2}$ are with the Department of Biology, Padjadjaran University, Jl. Raya Bandung-Sumedang km 21 Jatinangor 45363 INDONESIA.

N. Anggriani ${ }^{3}$ and A.K. Supriatna ${ }^{4}$ are with the Department of Mathematics, Padjadjaran University, Jl. Raya Bandung-Sumedang km 21 Jatinangor 45363 INDONESIA has been recommended for over 40 years until some failures are noticed [3].

The author in [4] pointed out that since 1970 hyperendemicity of dengue in many areas of tropical countries has been observed mainly due to the rapid and modern transportation that responsible in speeding the spread of dengue. However, many scientists also have shown that other mechanisms, such as insecticide resistence, is equally responsible [5]. The author in [4] has review some of the new and prospective programs in controlling the mosquitos in the future, mainly by the use of biological control agents.

Biological control includes the introduction of beneficial predatory or parasitic species into a natural systems where they were previously absent. The introduction is aimed to modify the natural system so that it could control the growth of the target species negatively which is otherwise the target species become pests or infectious agents [6]. There are some literatures discuss the use of some fungi to control the growth of insects, Metarhizium anisopliae and Beauveria bassiana are as the examples.

Metarhizium anisopliae is a anamorphic fungus which belong to the phylum Ascomycota. The reproductive structures of $M$. anisopliae comprise of conidiophores and conidia. Leveduriform structures or blastospores and appressoria are produced by $M$. anisopliae through mycelial differentiation. The fungal-host relationship occurs via the adhesion and germination of conidia on the surface of the insect, followed by hyphae penetration through the cuticle. Further discussion on how this relationship occurs and how this affect the mortality of the host is found in [7]. Similarly, Beauveria bassiana kills the host by infection as a result of the insect coming into contact with fungal spores. The spores germinate once they attached to cuticle of the insect and penetrate the insect's body to proliferate. Further discussion can be found in [8]. In this paper we report the preliminary results of our work on the application of two potential pathogenic fungi Metarhizium anisopliae and Beauveria bassiana in controlling the growth of the Aedes aegypti mosquitoes.

\section{II.PRELIMINARY RESULT}

The work was done in the Animal Taxonomy Laboratory Department of Biology Padjadjaran University for three 
months (April-June 2014). The aim of the work is to investigate the effect of pathogenic fungi Metarhizium anisopliae and Beauveria bassiana on the death rate of Aedes aegypti in two different life stages: larval and imago. Aedes larva and imago are exposed to the fungus with several different concentrations as seen in Table 1.

TABLE I

CONCENTRATION USED IN THE EXPERIMENT

\begin{tabular}{ccc} 
Concentration & Metarhizium anisopliae & Beauveria bassiana \\
\hline \hline $10^{-1}$ & $1,0968 \times 10^{9}$ & $54,6 \times 10^{9}$ \\
$10^{-2}$ & $2,152 \times 10^{8}$ & $21,2 \times 10^{8}$ \\
$10^{-3}$ & $0,4 \times 10^{6}$ & $1,7 \times 10^{6}$ \\
$10^{-4}$ & $0,2 \times 10^{5}$ & $1,5 \times 10^{5}$ \\
$10^{-5}$ & $0,9 \times 10^{3}$ & $0,6 \times 10^{3}$ \\
$10^{-6}$ & $1,52 \times 10^{2}$ & $0,3 \times 10^{2}$ \\
Control $(0)$ & 0 & 0 \\
\hline \hline
\end{tabular}

We look at the larval and imago death and counting the number of death up to 24 hours and 48 hours after the exposure to the fungus. The details of the experiment is reported somewhere else (in prep.). The following table is the preliminary results of the work.

TABLE II

THE Number Of DeATh Of AEDES LARVAL AND IMAgo CAuSED By THE EXPOSURE TO M. ANISOPLIAE AND B. BASSIANA COUNTED IN TwO DisCRETE TIME 24 HOUR AND 48 HOURS AFTER THE FIRST EXPOSURE.

\begin{tabular}{ccccccccc} 
Concentration & \multicolumn{2}{c}{ Metarhizium anisopliae } & \multicolumn{3}{c}{ Beauveria bassiana } \\
& \multicolumn{2}{c}{ Larva } & \multicolumn{2}{c}{ Imago } & larva & \multicolumn{2}{c}{ Imago } \\
& 24 & 48 & 24 & 48 & 24 & 48 & 24 & 48 \\
\hline \hline $10^{-1}$ & 16 & 24 & 23 & 29 & 16 & 19 & 26 & 30 \\
$10^{-2}$ & 10 & 23 & 21 & 25 & 10 & 14 & 21 & 27 \\
$10^{-3}$ & 10 & 19 & 15 & 19 & 5 & 8 & 18 & 24 \\
$10^{-4}$ & 6 & 12 & 11 & 15 & 4 & 6 & 15 & 19 \\
$10^{-5}$ & 5 & 14 & 7 & 19 & 2 & 3 & 8 & 15 \\
$10^{-6}$ & 3 & 9 & 3 & 12 & 0 & 0 & 3 & 10 \\
Control (0) & 0 & 0 & 0 & 0 & 0 & 0 & 0 & 0 \\
\hline \hline
\end{tabular}

We note that for the first four high concentration the number mosquito's death caused by the Metarhizium is higher than that caused by the Beauveria. However, if the fungi are introduced to the Aedes imago then the opposite is true. This needs further investigation.

\section{ACKNOWLEDGMENT}

This work is funded by the Ministry of Research, Technology, and Higher Education of the Republic of
Indonesia through the scheme of "Hibah Kompetensi DIKTI 2015".

\section{REFERENCES}

[1] D.J. Gubler, "Dengue and dengue hemorrhagic fever: its history and resurgence as a global public health problem". In: Gubler DJ, Kuno G (eds.) Dengue and Dengue Hemorrhagic Fever. CAB International, Wallingford, UK, 1997, pp. 1-22. http://dx.doi.org/10.1016/b978-0-443-06668-9.50077-6

[2] C.S. Lofgren, "Ultra-low volume applications of concentrated insecticides in medical and veterinary entomology", Annual Review of Entomology 1970, 321.

http://dx.doi.org/10.1146/annurev.en.15.010170.001541

[3] E.A.C. Newton and P. Reiter, "A model of the transmission of dengue fever with an evaluation of the impact of ultra-low volume (ULV) insecticide applications on dengue epidemics", American Journal of Tropical Medicine and Hygiene 1992, 47: 709-720.

[4] D.J. Gubler," Prevention and Control of Aedes aegypti-borne Diseases: Lesson Learned from Past Successes and Failures", AsPac J. Mol. Biol. Biotechnol. 2011, Vol. 19 (3): 111-114.

[5] J. Mallet, "The evolution of insecticie resistence: have the insects won?", Trends in Ecology and Evolution 1989, vol 4(11): 336-340. http://dx.doi.org/10.1016/0169-5347(89)90088-8

[6] S.R. Gliessman, "Agroecologia: processos ecológicos em agricultura sustentável”, Porto Alegre: UFRGS, 2001, 653p.

[7] P.V. Tiago, N.T. de Oliveira, E.A.L.A. Lima, "Biological insect control using Metarhizium anisopliae: morphological, molecular, and ecological aspects", Cienc. Rural vol. 44 no. 4 Santa Maria April 2014.

[8] D.W. Long, G.A. Drummond, E. Groden, "Horizontal transmission of Beauveria bassiana", Agriculture and Forest Entomology 2000, 2:1117.

http://dx.doi.org/10.1046/j.1461-9563.2000.00046.x 